\title{
Motorway as a barrier to dispersal of the threatened dragonfly Sympetrum depressiusculum (Odonata: Libellulidae): Consequence of mortality or crossing avoidance?
}

\author{
HANA ŠIGUTOVÁ ${ }^{1,2}$, FILIP HARABIŠ ${ }^{3}$, MICHAL HYKEL ${ }^{1}$ and ALEŠ DOLNÝ ${ }^{1,2}$ \\ ${ }^{1}$ Department of Biology and Ecology, Faculty of Science, University of Ostrava, Chittussiho 10, 71000 Ostrava, \\ Czech Republic; e-mails: sigutova.hanka@gmail.com, michalhykel@seznam.cz, ales.dolny@osu.cz \\ ${ }^{2}$ Institute of Environmental Technologies, Faculty of Science, University of Ostrava, 30. dubna 22, 70103 Ostrava, \\ Czech Republic \\ ${ }^{3}$ Department of Ecology, Faculty of Environmental Sciences, Czech University of Life Sciences Prague, Kamýcká 129, \\ 16521 Prague, Czech Republic; e-mail: harabis@fzp.czu.cz
}

Key words. Odonata, Libellulidae, behaviour, dispersal barrier, dragonflies, habitat fragmentation, mortality

\begin{abstract}
Infrastructure is one of the main causes of landscape fragmentation, which results in isolation and loss of populations. Although the negative effect of roads on insects is well documented, only a minority of studies has focused on roads in the context of barriers to dispersal. Flying species in particular have been neglected. We investigated the effect of a four-lane motorway as a barrier to the movement of an isolated population of the threatened dragonfly Sympetrum depressiusculum in an agricultural landscape in Central Europe. Generalized additive models were used to assess the motorway's effect on (i) the distribution of adult dragonflies in patches of terrestrial habitat surrounding their natal site, and (ii) individual flight behaviour (i.e. willingness or unwillingness to cross the motorway). Movement patterns of marked adults throughout the landscape were also investigated. During one season, significantly fewer adults were found at patches located on the far side of the motorway, indicating it has a barrier effect. Observations on flight behaviour revealed no apparent effect of the motorway. The possible barrier effect for the species studied was therefore presumed to be a consequence of road mortality. Our results indicate that the motorway may influence the dispersal of this threatened species of dragonfly, which is a habitat specialist with particular requirements for its terrestrial environment. Negative effects on other species with similar behaviour and strategy can be presumed. When establishing new habitats, carrying out reintroductions or translocations, it is necessary to consider that roadways may reduce population size and affect population dynamics by limiting dispersal.
\end{abstract}

\section{INTRODUCTION}

Landscape fragmentation and degradation of natural habitats are direct consequences of recent human activity (Hanski \& Ovaskainen, 2000). Agricultural land consists of a mosaic of microhabitats, only a portion of which are favourable habitats. In combination with fragmentation, these limitations can lead to isolation and loss of populations (Mader et al., 1990; Thomas, 2000; Forman et al., 2003). Even though infrastructure is one of the main causes of landscape fragmentation (Findlay \& Houlahan, 1997; Van Bohemen, 1998), the issue of its effect on wildlife is long neglected. Once this came more to the forefront of concern, the majority of studies focused primarily on mammals and birds and, less frequently, on amphibians and reptiles (Spellerberg, 1998; Trombulak \& Frissell, 2000). Insects, meanwhile, remained only a marginal group for study, despite the fact that it is a species-rich taxon with rapid generation times and is therefore a good indicator as to the ecological effect of roads (Askling \& Bergman, 2003). The negative effect of roads on various groups of animals is nevertheless well known, and insects are no exception in that regard (Trombulak \& Frissell, 2000; Jones \& Bond, 2010; Jackson \& Fahrig, 2011; reviewed by Muñoz et al., 2015). There is evidence that roads negatively affect both the abundance and diversity of insects (Muñoz et al., 2015). The negative effect of roads is manifested in three main ways. First, roads are a barrier to the movement of individuals (Bhattacharya et al., 2003; Keller \& Largiadèr, 2003). Second, they constitute a direct source of mortality due to collisions with vehicles (Seibert \& Conover, 1991; Rao \& Girish, 2007). Third, roads are a considerable source of pollutants (Martel, 1995; Petranka \& Doyle, 2010).

In recent decades, a number of studies have focused on the effect of roads on various groups of insects. Only a fraction of these, however, have examined this issue in the 
context of barriers to the dispersal of individuals. Within this fraction, moreover, flying insects as a target group have accounted for only a negligible number of studies, probably reflecting a general belief that roads constitute a barrier mainly for small and flightless species (Noordijk et al., 2006). Roads may, however, also pose a barrier to the movement of flying individuals, not only via direct mortality during crossing attempts but also by influencing behaviour such as the animals' unwillingness to cross (e.g. Forman et al., 2003). This barrier effect occurs because roads constitute a specific formation in the landscape with characteristics different from those of their surroundings in terms of, for example, temperature, thermodynamics and polarized light (Kriska et al., 1998; Seiler, 2001). It is well proven that many invertebrates react significantly to differences in the microclimate and openness of the substrate between the road surface and its verge (Mader, 1988; Mader et al., 1990). For instance, Dennis (1986) observed a high incidence of crossing avoidance in certain butterfly species. These factors may thus also have a significant effect on the behaviour of dragonflies. Most studies on this group, however, deal with road mortality (Muñoz et al., 2015). According to Riffel (1999), in many dragonfly species females are more susceptible to collisions with vehicles. This may be due to the different behaviour patterns of females inasmuch as they more frequently fly further from their aquatic habitats to find food sources and avoid harassment from males (Foster \& Soluk, 2006). Butterflies, on the other hand, may exhibit exactly the opposite trend (McKenna et al., 2001; Rao \& Girish, 2007). Askling \& Bergmann (2003) show that in butterflies the barrier effect of roadways is species-dependent. Another study proves that the barrier effect of roads on butterflies manifests itself differently for open versus closed populations and indicates that roads should not be a barrier for groups with higher movement capability (Munguira \& Thomas, 1992), but specific analyses of this proposition are lacking (Muñoz et al., 2015). Direct observations of dragonfly flight behaviour indicate that roadways probably do not cause immediate crossing avoidance but, depending on the species, may result in an increase in their mortality (Rao \& Girish, 2007; Soluk et al., 2011).

From a conservation perspective, dragonflies are good indicators of the magnitude of the ecological effect of roads on insects because of their sensitivity to landscape fragmentation (Muñoz et al., 2015) and relatively longlived adult stages (Soluk et al., 2011). In general, populations of rare and endemic species are more susceptible to barrier effects and isolation. Moreover, species with extensive home ranges and large area requirements will need to cross roads more frequently than the smaller and less mobile species (Seiler, 2001). This might be the case for Sympetrum depressiusculum (Selys) (Odonata: Libellulidae), a habitat specialist that is threatened because its natural habitats have mainly vanished throughout Europe and which now persists mainly in local, isolated populations. In the European Red List, it is ranked as vulnerable, and it is redlisted throughout Central and Western Europe (Kalkman et al., 2010). Despite strong philopatry, the home range of $S$. depressiusculum is relatively extensive and the species requires a diversity of terrestrial habitats because individuals use various habitats at different times during its maturation and adulthood, even at considerable distances from their aquatic habitats (Dolný et al., 2013, 2014; Hykel et al., 2016). It is therefore likely that the potential barrier effect of a roadway in the vicinity of a natal site would prevent this species dispersing throughout the landscape and thus reduce the possibility of it colonizing suitable new habitats that are sparsely distributed.

The present study investigated the effect of a four-lane motorway as a barrier to the movement of adult $S$. depressiusculum. Specifically, the aims were to investigate:

(i) whether the presence of a motorway affects this dragonflies' distribution around its natal site and use of terrestrial habitats;

(ii) whether there is any effect on behaviour, such as an unwillingness to cross the motorway; and

(iii) the movement patterns of $S$. depressiusculum throughout the landscape.

\section{MATERIAL AND METHODS}

\section{Study site}

This study was conducted during 2014-2016 within the River Sedlnice catchment in the northeast of the Czech Republic. At this specific location, a numerous population of Sympetrum depressiusculum persists in a single farm pond $\left(49^{\circ} 38^{\prime} 05.6^{\prime \prime} \mathrm{N}\right.$, $\left.18^{\circ} 06^{\prime} 04.3^{\prime \prime} \mathrm{E}\right)$ used annually for rearing common nase (Chondrostoma nasus). In the vicinity of the pond are four variously managed farm ponds that are unfavourable environments for this species of dragonfly (Šigutová et al., 2015), and all five ponds are surrounded by an agricultural landscape (mainly variously managed agricultural fields and hay meadows) with remnants of a floodplain forest. To the north of the natal site, at a distance of about $200 \mathrm{~m}$, the landscape is intersected by the four-lane E462 motorway. This section of motorway has a maximum speed limit of $100 \mathrm{~km} / \mathrm{h}$ and average annual daily (24 h) traffic count of 13035 vehicles ( $\breve{R S D} \breve{C R}, 2015$ ). Both sides of the road offer similar types of patches of terrestrial habitat (Fig. 1). The study site is isolated, with the closest known population of $S$. depressiusculum occurring about $100 \mathrm{~km}$ from the target locality (Dolný \& Šigutová, pers. observ.).

\section{Field sampling}

\section{Effect of motorway on the distribution of adults}

To investigate whether the motorway acts as a barrier to the movement of adults and how it affects their distribution, 27 habitat patches $(10 \times 10 \mathrm{~m})$ were delineated at distances of 300 and $500 \mathrm{~m}$ from the natal site. Each patch on both sides of the motorway was assigned to a particular habitat: ruderal area or abandoned field (both marked as "abandoned area" in Fig. 1), arable field, or grassland. These habitat patches were of similar quality on both sides of the road (similar vegetation cover and structure, land use). During sampling, 13 individual walks were made at regular intervals during the main species flight period (between 25 July and 17 September 2014). During these walks, monitored patches were visited and the abundance of adult individuals recorded. All observations were conducted between 1000 and $1600 \mathrm{~h}$ CEST only on windless days with cloud cover less than $20 \%$. This survey was repeated in 2016 (2 August - 11 September) but only at 21 habitat patches at a distance of $300 \mathrm{~m}$, and 


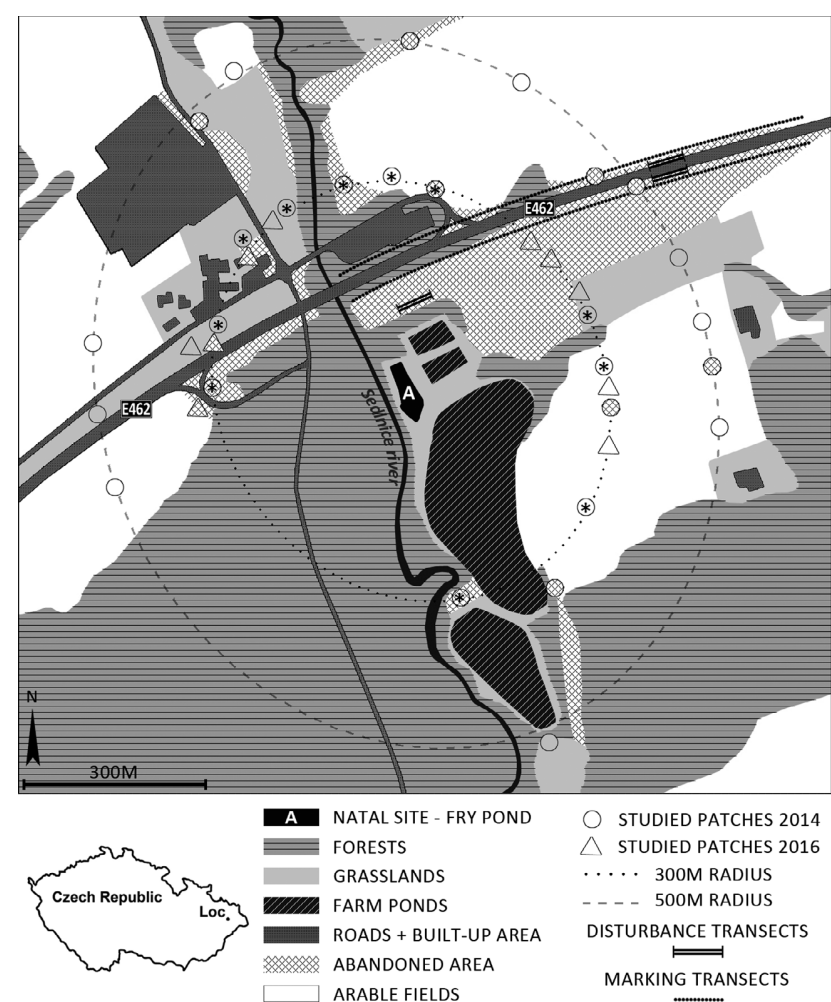

Fig. 1. Location and detailed map of the study area showing the natal site and location of the transects. Patches marked with asterisks were studied in both 2014 and 2016.

12 individual walks were made. Some of the patches also studied in 2014, however, had to be slightly shifted or their locations had to be completely changed because of changes in the landscape (mainly due to different management practices in the fields and hay meadows). During both seasons, the management (i.e. such disturbances as mowing the meadows or harvesting the fields) of the patches were recorded

\section{Effect of motorway on flight behaviour}

The potential avoidance behaviour resulting in adults not crossing the motorway was investigated directly by means of observations along three transects (each $50 \mathrm{~m}$ long and $10 \mathrm{~m}$ wide). In an area about $450 \mathrm{~m}$ distant from the natal site (see Fig. 1), two transects were placed parallel to the motorway with the midline $10 \mathrm{~m}$ from the edge of the motorway and one along each side. As a control, one transect was placed in a field $50 \mathrm{~m}$ from the motorway. There was no direct view of either the motorway or natal site from the control transect. All surveys were conducted between 1000 and $1500 \mathrm{~h} \mathrm{CEST}$ in random order at each session in the species' main flight period during July-September 2015. Eleven walks were made along each transect. During these walks, adults were disturbed while roosting and the direction of their escape flight recorded. Three possible directions were distinguished: (i) directly upwards (i.e. individuals just flew up and returned to the area from which they were disturbed), (ii) towards a field/meadow, or (iii) towards the motorway. It should be noted that such behaviour was tested only for sections without high vegetation, where only the motorway was a barrier to dispersal.

\section{Movements of adults throughout the landscape}

Two transects (each $850 \mathrm{~m}$ long and $10 \mathrm{~m}$ wide, placed parallel to the road, with the midline $25 \mathrm{~m}$ from the motorway) were established to investigate the pattern of adults' movements in relation to the motorway. Every transect was divided into 11 sub- sections, each of which was $50 \mathrm{~m}$ long. Between 3 August and 29 September 2014 (covering the main flight period of adults), eight walks were made at regular intervals (approximately 7 days) along each subsection. Unmarked and marked individuals of both sexes were sought. Captured individuals were marked on the wings using a unique code with a permanent marker and later released into the middle of the subsection within which they were captured. Crossings by adults that were not captured were also recorded. The capture-mark-recapture study was simultaneously conducted at the natal site. During the flight season of $S$. depressiusculum (between 7 July and 30 September 2014) 25 individual walks were made along transects $5 \mathrm{~m}$ wide on the embankment. Each individual captured (either teneral, juvenile or adult) was marked on the wings using a unique code. Marking was carried out at regular intervals (depending on weather conditions). The length of individual walks around the perimeter of the pond was equal in order to avoid uneven distribution of samples in time (season) and space. Captured individuals that were previously marked at subsections in the vicinity of roads were noted. The movements of all marked adults that crossed the motorway (either from transects or the natal site) were recorded.

\section{Data analyses}

Because seasonal changes in the abundance of individuals were initially expected, the overall effect of the motorway on the distribution of adults was analyzed using a generalized additive model (GAM) with integrated smoothness estimation in the mgcv 1.8-11 package (Wood, 2006). The "gam" function with restricted maximum likelihood (REML) was used for smoothness selection (Wood, 2011). Inasmuch as it was not possible to consider patches at the same locations as (qualitatively) similar in various years, data for individual years were evaluated in separate models. In these models with negative binomial distributions, the abundance of adults was always the response variable while habitat type, management, position in relation to the road and distances from the natal site were explanatory variables. The GAM was used with negative binomial distribution of errors to assess the effect of the motorway on individual flight behaviour. Three separate models for different locations (near side of the road, far side of the road and control) were utilized for the overall comparison. In these models, the abundance of individuals was always the dependent variable and the direction of flight the independent variable. In all models, the temporal variation in abundance was included as a smoothing term of the variable period. All analyses were performed in R 3.2.2 (R Development Core Team, 2015).

\section{RESULTS}

\section{Effect of motorway on the distribution of adults}

In both years, abundances of adults at individual habitat patches on the far side of the motorway differed significantly from those at patches on the near side of the motorway $\left(F_{2014}=8.80, P=0.003 ; F_{2016}=7.87, P=0.005\right.$, respectively). Situation in 2016 , and at the beginning of 2014 season, when the abundances of adults at individual habitat patches on the far side of the motorway were significantly lower, indicated that the road was a barrier to adult movement (Fig. 2). However, this situation may vary significantly over time depending on disturbances related to management practices (mowing, harvesting). In 2016, management had no significant effect on the occupancy of individual patches $(F=0.12, P=0.727)$. In 2014, however, management activities were so asymmetrical as to completely change the occupancy of patches on both sides of 
a)

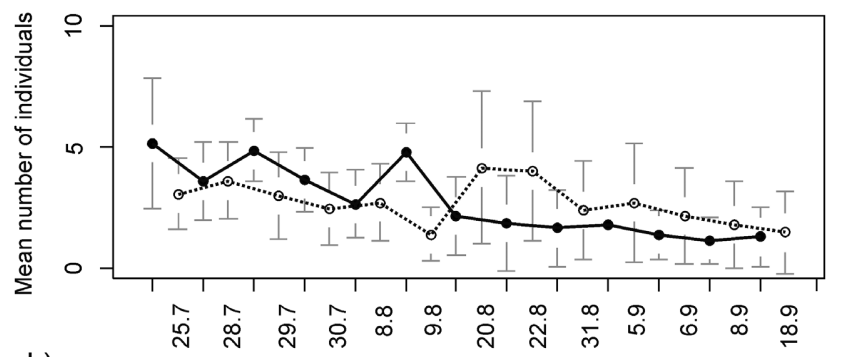

b)

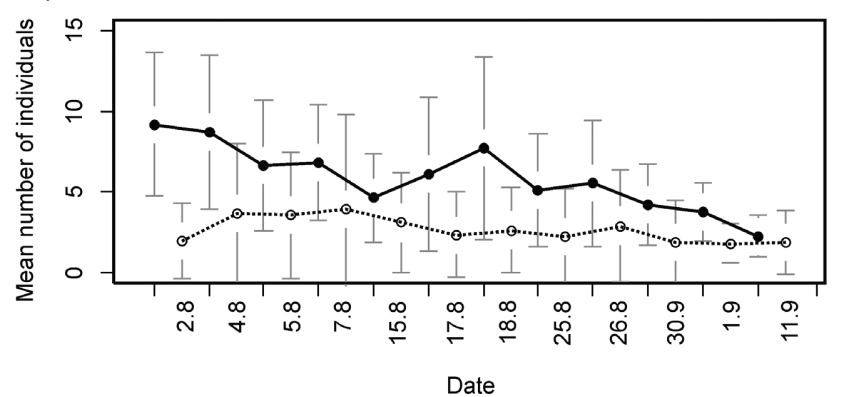

Fig. 2. Mean number of individuals of $S$. depressiusculum recorded in patches of habitat on the near (solid line) and far side (dashed line) of the four-lane E462 motorway in the north-east of the Czech Republic in 2014 (a) and 2016 (b). In both years, the abundance of adults in particular habitats on the far side of the motorway were significantly different from those on the near side, which indicates that the road was a barrier to adult movement, at least in 2016. Error bars represent $95 \%$ confidence intervals.

the $\operatorname{road}(F=4.54 ; P=0.034$; Fig. 3$)$. The abundance of individuals depended significantly on the type of habitat $\left(F_{2014}=26.69, P<0.001 ; F_{2016}=3.75, P=0.025\right.$, respectively), with adults preferring ruderal areas, while the effect of the distance of a particular habitat patch from the natal site was not significant $\left(F_{2014}=0.19, P=0.66\right)$.

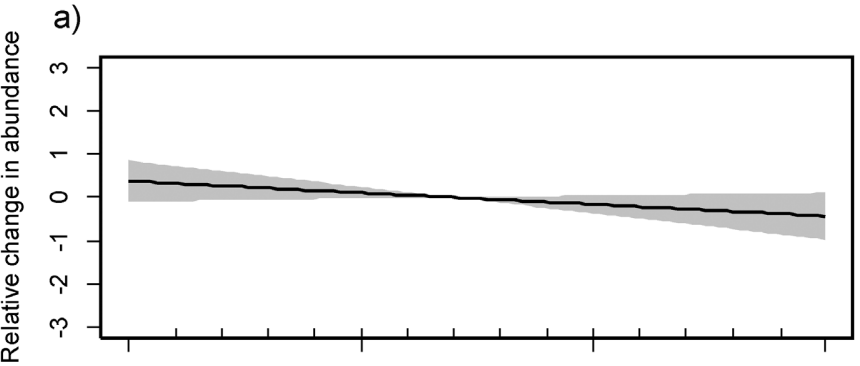

c)

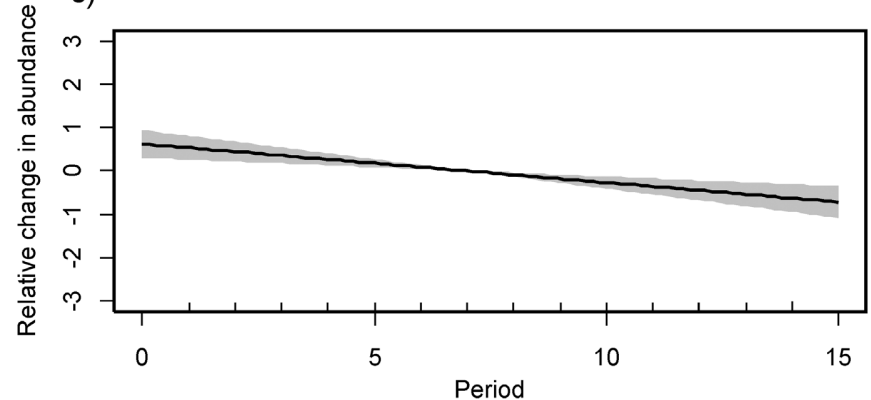

a)

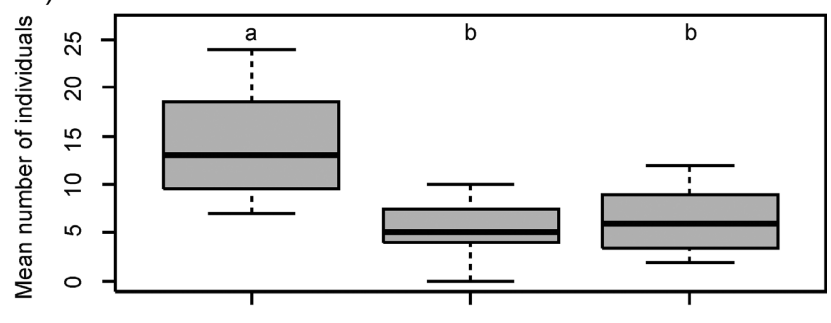

b)

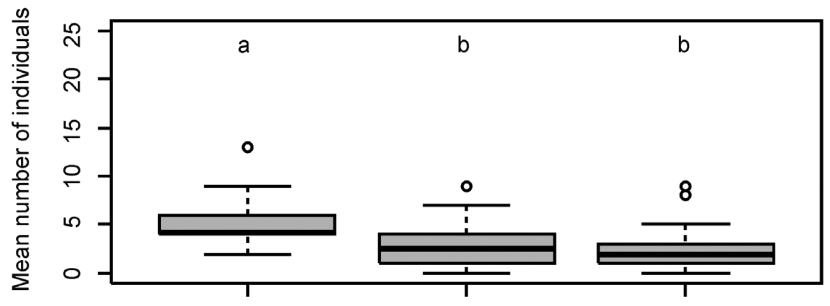

c)

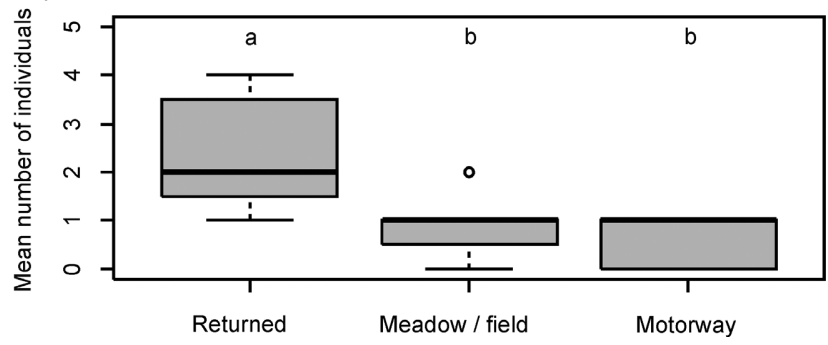

Fig. 4. Direction of the escape flights of adults of $S$. depressiusculum disturbed in linear transect (a) control, (b) on the near side of the motorway and (c) far side of the motorway. Possible directions were: directly upwards (returning to the same area from which they were disturbed), towards a meadow/field, or in the opposite direction towards the motorway. Most individuals returned to the same area from which they were disturbed but the direction of escape flights from all transects was random and the motorway had no apparent effect of on the behaviour of the adults. Superscripts a and $b$ represent significant differences between mean number of individuals flying in particular directions.

b)

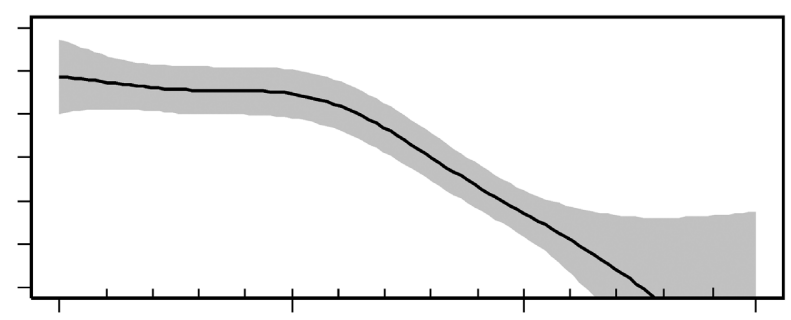

d)

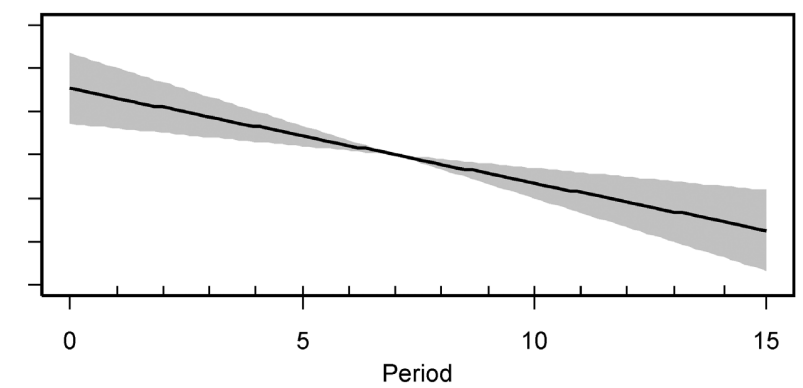

Fig. 3. Relative changes in the abundance of $S$. depressiusculum over the whole period of the study (between 25 July and 17 September 2014) in terrestrial habitats on the near side (a, b) and far side (c, d) of the four-lane E462 motorway in the north-east of the Czech Republic in 2014, which indicates that the disturbances at habitats on the near side (b) and far side (d) of the motorway differed in their effect. Relative changes in abundance of individuals at undisturbed patches were very similar (a, c). Shaded bands represent $95 \%$ confidence intervals. 
Table 1. Numbers of marked and recaptured individuals of Sympetrum depressiusculum recorded at the natal site and along linear transects during its flight season in 2014.

\begin{tabular}{|c|c|c|c|c|}
\hline Location & Marking days & Marked $(\lesssim / Q)$ & Recaptured $(\hat{\jmath} / \varphi)$ & Capture events $(\delta / P)$ \\
\hline Natal site & 25 & $1,635 / 1,366$ & $18 / 13$ & $1,653 / 1,379$ \\
\hline \multicolumn{5}{|l|}{ Linear transects } \\
\hline Near side of the motorway & 8 & $228 / 38$ & $7 / 1$ & $235 / 39$ \\
\hline Far side of the motorway & 8 & $143 / 38$ & $6 / 1$ & 149/39 \\
\hline$\Sigma$ & 30 & $2,006 / 1,442$ & $31 / 15$ & $2,037 / 1,457$ \\
\hline
\end{tabular}

\section{Effect of motorway on flight behaviour}

Observations of escape flights revealed that most individuals returned to the same area from which they were disturbed (control: $F=17.95, P<0.001$; near side of the road: $F=15.69, P<0.001$; far side of the road: $F=14.26$, $P<0.001)$, but the direction of escape flights recorded along transects was random with no apparent effect of the motorway on adult behaviour (Fig. 4).

\section{Movements of adults throughout the landscape}

In 2014, a total of 3,448 individuals were marked. Of these, 46 adults were recaptured (Table 1 ). The majority of recorded movements were related to displacements within the natal site (31), and only 12 movements were recorded between the natal site and the linear transects located on both sides of the road. Of these, 5 movements were from the natal site to a terrestrial habitat while 7 individuals headed in the opposite direction. Of these 12 movements, seven $(=58 \%)$ were across the road. Ten displacements solely within a terrestrial habitat were recorded, out of these, seven (=70\%) were across the road (Fig. 5).

\section{DISCUSSION}

Understanding whether roads act as barriers is essential to developing successful species management programs for many threatened species, but such information is largely unavailable for most insect taxa (Shepard et al., 2008; Muñoz et al., 2015). Our results indicate that the motorway did not result in avoidance behaviour by adults of $S$. depressiusculum but did act as a barrier to their movement

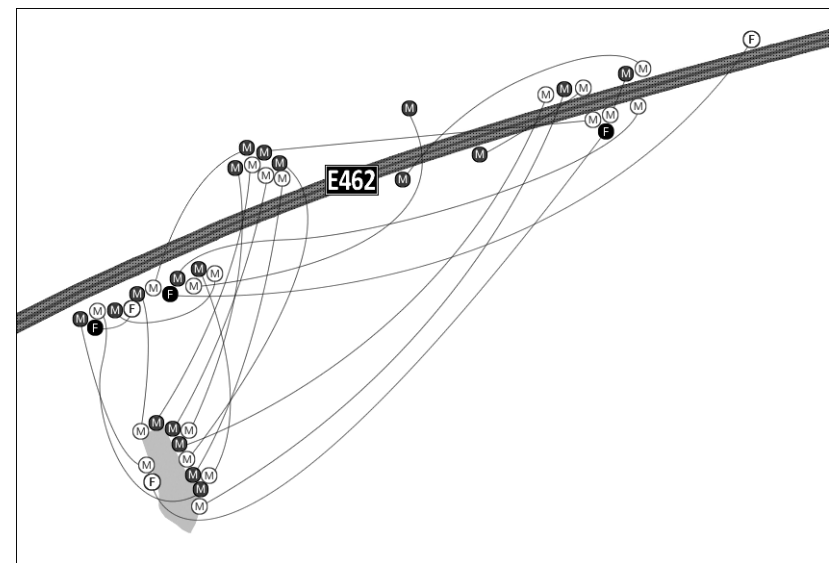

Fig. 5. Movements of Sympetrum depressiusculum recorded in the vicinity of and on the far side of the E462 motorway in the north-east of the Czech Republic in 2014. Dark coloured circles indicate captured individuals and light coloured circles recaptures ( $\mathrm{M}$ - male, $\mathrm{F}$ - female). within the terrestrial environment, at least in 2016. The majority of studies focusing on the barrier effect of roads are notably biased towards road mortality, while studies on avoidance behaviour are rare (Shepard et al., 2008). Similarly, most studies focus on insects killed by vehicles during crossing attempts and predominantly target flightless species. In their review, Muñoz et al. (2015) conclude, however, that flight itself does not ensure that species are not affected by the barrier effect of roads. In other words, the ability to fly does not mean that an individual will try to cross or that if it does so it will succeed in reaching the other side.

Several studies have attempted to quantify roadkill events of flying insects and found significant variation in mortality between orders and depending on traffic volume (e.g. Munguira \& Thomas, 1992; Yamada et al., 2010; Skórka et al., 2013; Baxter-Gilbert et al., 2015). Some have even focused on dragonflies (e.g. Seibert \& Conover, 1991; Riffell, 1999; Rao \& Girish, 2007; Soluk et al., 2011). These studies were based on counting insect carcasses on the road surface and its verge, but many dead individuals may be expected to have remained stuck on a vehicle after collision, been blown away by the vehicle's slipstream, or removed as prey (Seibert \& Conover, 1991; McKenna et al., 2001). These events can be expected especially in the case of teneral individuals, whose exoskeleton is still soft. According to Corbet (1999), however, most dragonflies disperse during the teneral stage. Given these circumstances, the real number of individuals killed by vehicles during crossing attempts is probably underestimated (Soluk et al., 2011). Moreover, the results and conclusions of such studies dramatically differ according to the methodology used (Muñoz et al., 2015). Therefore, although our study did not attempt to quantify the mortality rate of the $S$. depressiusculum that attempted to cross the road, it does provide a comprehensive assessment of the barrier effect of a motorway by combining two approaches: a direct observation of the behavioural response to a road and observations of the distribution of adults in an landscape intersected by a motorway. Because no behavioural response of disturbed $S$. depressiusculum adults to the presence of the four-lane motorway was observed, and there were considerably fewer adults in patches of terrestrial habitat on the side of the motorway furthest from the natal site, at least during one season, it is presumed that in this case the possible barrier effect is the consequence of road mortality. This hypothesis is supported by the fact that when walking along marking transects adults were often seen flying towards and over the motorway; however, further investiga- 
tion is necessary to provide empirical evidence of roadway mortality.

A similar conclusion was reached by Soluk et al. (2011), who deduce that roads are not barriers for adult dragonflies. These authors expect, however, that the mortality in crossing roads is species-specific, and depends on their flight agility and average flight height. Species with low flight trajectories are subject to higher mortality during crossing attempts, but those with greater flight agility are able to avoid collisions with passing vehicles despite their low flight height. Mortality may be associated not only with a species' flying ability but also with the characteristics of roads. In the case of butterflies, for example, mortality is positively correlated with road width, because an individual spends more time above the road surface in the case of a wider road, which increases the probability of it colliding with passing vehicles. It is not surprising, therefore, that small species are more likely to be killed when crossing roads (Skórka et al., 2013). Moreover, mortality is positively correlated with traffic volume and speed (Forman \& Alexander, 1998; Soluk et al., 2011). The average traffic volume in our study $(13,035$ vehicles per day with a maximum speed limit of $100 \mathrm{~km} / \mathrm{h}$ ) was greater than that recorded in most of the studies on the mortality of dragonflies. Because adults of $S$. depressiusculum are typical perchers and, due to their wavering flight, are not agile flyers (Sternberg \& Buchwald, 2000), a significant level of roadkill events may be expected in this species. In our study, the average width of the road in the monitored section was $16 \mathrm{~m}$. From this point of view, road kills may be expected especially among juveniles, whose flight abilities are not yet fully developed.

Another aspect of the barrier effect is the motivation to cross a motorway. Given that in our study there were similar patches of terrestrial habitat on both sides of the motorway and that disturbed adults were not reluctant to cross the motorway it is possible that when not disturbed adults will not cross if the food supply is plentiful. This has been documented for bumblebees, which are reluctant to cross infrastructure barriers unless seeking other foraging sites (Bhattacharya et al., 2003). For butterflies, air currents along road verges are considered to constitute one of the main mechanisms repelling individuals from crossing roads (Muñoz et al., 2015). Juveniles of $S$. depressiusculum may react similarly, but there is no evidence to support this hypothesis. Overall, our study indicates that a fourlane motorway may act as a barrier to the movement of S. depressiusculum. According to Soluk et al. (2011), the long adult lifespan of dragonflies makes them one of the few invertebrate groups likely to be affected by roadways. Given that adults of $S$. depressiusculum spend an average 3 months in a terrestrial environment and utilize a mosaic of terrestrial habitats (Dolný et al., 2014), the presence of a motorway is likely to have consequences for this species, not only by preventing its dispersal and colonization of new habitats but also by reducing the availability of potentially suitable habitats, but also in terms of its abundance as it results in an increase in the rate of mortality. Taking into account the isolation of populations and this species' specific habitat requirements (Sternberg \& Buchwald, 2000; Schmidt, 2008), the barrier effect of roads could probably be even more serious.

Several studies have shown that landscape structure or landscape connectivity may be important factors shaping dragonfly distribution (e.g. Raebel et al., 2012; Baguette \& Van Dyck, 2007). However, such influences may be species- and landscape-specific, and range from high to negligible (Baguette \& Van Dyck, 2007; Bolliger et al., 2011). According to our previous study on the dispersal behaviour of $S$. depressiusculum in the same area, abandoned fields and extensively used hay meadows are attractive habitats for adults, whereas water bodies in the vicinity of the natal site are attractive only during the last third of the flight period and arable fields only prior to harvesting (Dolný et al., 2014). In the present study, we took the above results into consideration in choosing patches of habitat in order to minimize the effect of landscape structure on the distribution of the adults and ensure the connectivity between the natal site and all the patches studied. As abandoned fields previously proved to be highly attractive for adults, we suggest that they might have acted as important "stepping stones" from the natal site towards the motorway and beyond, and as the arable fields were harvested in the last third of the study period, we assume that landscape connectivity was maintained during most of the study period. However, our results should be treated with caution, and for more general conclusions, multiple populations in various landscapes should be investigated, which, given this species' current distribution, is currently impossible.

In accordance with the original assumptions, the abundance of individuals depended significantly on type of habitat. Moreover, Hykel et al. (2016) conclude that the abundance of adult $S$. depressiusculum is positively correlated with vegetation cover and heterogeneity. This could explain the observed seasonal changes in abundance at individual habitat patches. In 2014, a drop in abundance in a particular habitat was always related to some preceding management (mowing or harvesting) independent of distance from the natal site. The relationship between vegetation and occupancy is thus self-explanatory. The sudden increase in occupancy of habitats located on the far side of the roadway and decrease on the near side in the middle of the flight season in 2014 was in fact a consequence of harvesting of farm fields and mowing of meadows, which again accords with the observations of Dolný et al. (2014). In 2016, the effect of management was not apparent, probably due to different timing. Mowing of meadows and harvesting of farm fields occurred (with a single exception) at the end of the study period and thus before the last visit to the habitat patches. At this time there is usually a decrease in the abundance of adults, whose numbers continue to decline as the flight period ends. Moreover, these activities occurred simultaneously on both sides of the motorway. The negative effect of mowing on dragonfly abundance is well known (Sternberg \& Sternberg, 2004; Wildermuth, 2012; Dolný et al., 2014) as dense vegetation provides 
shelter and sources of food (Buchwald, 1992; Sternberg \& Buchwald, 2000; Foote \& Hornung, 2005; Zahn et al., 2010; Harabiš, 2016). Changes in abundance in terrestrial habitats may also be associated with the abundance of this species at the natal site, as in the main period of mating activity there is high abundance (competition) at the natal site. In 2014, however, no links were found between seasonal dynamics of adults at the natal site (Šigutová, unpubl.) and changes in the abundance in terrestrial habitats. This also supports the notion that vegetation cover and structure are key factors explaining seasonal changes in the distribution of adults.

Individuals at the natal site and along the transects were marked in order to assess patterns of movement throughout the landscape in relation to the motorway. However, the population studied in 2014 was very numerous $(300,000$ adults based on a capture-mark-recapture study; Šigutová, unpubl.), which resulted in a very low proportion of the adults being marked despite an intensive sampling effort covering the entire flight period of the adults. Although a great effort was made to mark the maximum number of individuals, and especially teneral individuals, whose concentration at the natal site was enormous, the overall recapture rate was negligible $(1.3 \%)$. Of the total of 1671 teneral individuals and juveniles marked at the natal site, only 2 mature males were recaptured along the transects and both had crossed the road. The rest of the individuals recaptured along transects were marked as mature adults. The total number of individuals captured at the natal site was only slightly biased in favour of males. In contrast, along the transects, different proportions of males and females were recorded: on near side of the motorway $14.3 \%$ were females and on the far side it was $21 \%$. This is in concordance with Foster \& Soluk (2006), who propose that females usually fly further from their aquatic habitats in search of food and in order to avoid male harassment (also Michiels \& Dhondt, 1989). Of a total of 46 recaptures only 14 had crossed the motorway $(30.4 \%$ of all recaptures). However, of all the movements recorded within the natal site and along and within terrestrial transects the majority had crossed the road $(58 \%$ and $70 \%$, respectively), indicating that the road may not have been a barrier. Moreover, when the isolation of the population studied is taken into consideration, the number of successful crossings of the road increases as the individuals marked at the transect located on the far side of the motorway must have crossed it when flying from the natal site. But is this number high enough? According to Seiler et al. (2001), the permeability rate sufficient to maintain habitat connectivity is determined by consequences at the population level, which depend on the number of successful crossings relative to population size, mobility and individuals' area requirements. In butterflies, vulnerability is more closely related to a species' ability to colonize new habitats, which is also partially related to flight ability (Askling \& Bergman, 2003). According to Soluk et al. (2011), even a small proportion of individuals killed during crossing attempts can have short- and long-term consequences for dragon- fly populations, especially if the mortality rates of males and females differ. Since $S$. depressiusculum females have a stronger tendency to disperse (Dolný et al., 2014), they may also be expected to suffer a higher frequency of collisions with passing vehicles. Although the studied population of $S$. depressiusculum is very numerous, its survival depends on a single artificial farm pond (natal site). Thus, even a relatively small change in management can have significant consequences for this population (Šigutová et al., 2015). Due to their specific habitat requirements, adults of $S$. depressiusculum have very little chance of finding and colonizing new habitats, which is probably further reduced by the road network restricting the movement of adults and their dispersal throughout the landscape. Thus, the effect of the motorway in the close vicinity of the natal site could have far-reaching consequences, especially in the event of a dramatic reduction in population size.

\section{CONCLUSION}

The total length of European motorways nearly doubled in the period from 1990 to 2013. European road networks, traffic volumes and speeds will continue to increase for the foreseeable future (European Commission, 2016). Therefore, road construction is undoubtedly an important factor affecting the spatial structure of invertebrate populations. Our study indicates that a motorway may affect the dispersal of a threatened species of dragonfly, a habitat specialist with specific requirements for its terrestrial environment, and such an effect may be presumed also for other species of dragonflies with similar behaviour and strategies. To understand the barrier effect of roads and develop effective management plans for species at risk, it is necessary to determine the precise level of road mortality and its effect on the population ecology and behaviour of the species studied (Shepard et al., 2008). According to Seiler (2001), choosing between alternative routes for a new road may help to prevent dissecting local populations of small species. In the case of an existing barrier, however, it is necessary to reduce its negative effect. In establishing new habitats, reintroductions or translocations as a part of conservation management it is necessary to take the effect of roadways into account as one of the factors possibly reducing population size and affecting population dynamics by limiting dispersal.

ACKNOWLEDGEMENTS. We thank A. Šimara and M. Kudělka for their help with fieldwork. This paper was written as part of an Institute of Environmental Technologies project. Financial support through Project CZ.1.05/2.1.00/03.0100 (IET) financed by the Structural Funds of the European Union and Project LO1208 of the National Feasibility Programme I of the Czech Republic as well as support from the Grant Agency of University of Ostrava (SGS33/ PrF/2014, SGS24/PrF/2016) and M. Roeselová Memorial Fellowship are gratefully appreciated.

\section{REFERENCES}

Askling J. \& Bergman K.-O. 2003: Invertebrates - a forgotten group of animals in infrastructure planning? Butterflies as tools and model organisms in Sweden. In Irwin C.L., Garrett P. \& McDermott K.P. (eds): Proceedings of the 2003 International 
Conference on Ecology and Transportation. Center for Transportation and the Environment, North Carolina State University, Raleigh, NC, pp. 476-482.

Baguette M. \& VAN Dyck H. 2007: Landscape connectivity and animal behavior: Functional grain as a key determinant for dispersal. — Landsc. Ecol. 22: 1117-1129.

BaXter-Gilbert J.H., Riley J.L., Neufeld C.J.H., Litzgus J.D. \& LESBARRĖRES D. 2015: Road mortality potentially responsible for billions of pollinating insect deaths annually. - J. Insect Conserv. 19: 1029-1035.

Bhattacharya M., Primack R.B. \& Gerwein J. 2003: Are roads and railroads barriers to bumblebee movement in a temperate suburban conservation area? - Biol. Conserv. 109: 37-45.

Bolliger J., Keller D. \& Holderegger R. 2011: When landscape variables do not explain migration rates: An example from an endangered dragonfly, Leucorrhinia caudalis (Odonata: Libellulidae). — Eur. J. Entomol. 108: 327-330.

BUCHWALD R. 1992: Vegetation and dragonfly fauna - characteristics and examples of biocenological field studies. - Vegetatio 101: 99-107.

CoRbet P.S. 1999: Dragonflies: Behavior and Ecology of Odonata. Harley Books, Colchester, 829 pp.

DenNIS R.L.H. 1986: Motorways and cross-movements. An insect's "mental map"of the M56 in Cheshire. - Bull. Amat. Entomol. Soc. 45: 228-243.

DolnÝ A., MižIČová H. \& Harabiš F. 2013: Natal philopatry in four European species of dragonflies (Odonata: Sympetrinae) and possible implications for conservation management. $-J$. Insect Conserv. 17: 821-829.

DolnÝ A., Harabiš F. \& MižIČová H. 2014: Home range, movement, and distribution patterns of the threatened dragonfly Sympetrum depressiusculum (Odonata: Libellulidae): A thousand times greater territory to protect? - PLOS ONE 9: e100408, $10 \mathrm{pp}$.

EUROPEAN COMMISSION 2016: Mobility and Transport - Statistical Pocketbook 2016. URL: http://ec.europa.eu/transport/factsfundings/statistics/pocketbook-2016 en (last accessed 12 Dec. 2016).

Findlay S.C. \& Houlahan J. 1997: Anthropogenic correlates of species richness in Southeastern Ontario wetlands. - Conserv. Biol. 11: 1000-1009.

Foote A.L. \& Hornung C.L. 2005: Odonates as biological indicators of grazing effects on Canadian prairie wetlands. - Ecol. Entomol. 30: 273-283.

Forman R.T.T. \& AleXANDER L.E. 1998: Roads and their major ecological effects. - Annu. Rev. Ecol. Syst. 29: 207-231.

Forman R.T.T., Sperling D., Bissonette J.A., Clevenger A.P., Cutshall C.D., Dale V.H., Fahrig L., France R., Goldman C.R., Heanue K. et Al. 2003: Road Ecology. Island Press, Washington, DC, $504 \mathrm{pp}$.

Foster S.E. \& Soluk D.A. 2006: Protecting more than the wetland: The importance of biased sex ratios and habitat segregation for conservation of the Hine's emerald dragonfly, Somatochlora hineana Williamson. - Biol. Conserv. 127: 158-166.

HANSKI I. \& OVASKAINEN O. 2000: The metapopulation capacity of a fragmented landscape. - Nature 404: 755-758.

HARABIŠ F. 2016: The value of terrestrial ecotones as refuges for winter damselflies (Odonata: Lestidae). - J. Insect Conserv. 20: 971-977.

Hykel M., Harabiš F. \& DolnÝ A. 2016: Assessment of the quality of the terrestrial habitat of the threatened dragonfly, Sympetrum depressiusculum (Odonata: Libellulidae). — Eur. J. Entomol. 113: 476-481.
JACKSON N.D. \& FAHRIG L. 2011: Relative effects of road mortality and decreased connectivity on population genetic diversity. - Biol. Conserv. 144: 3143-3148.

JoNES D.N. \& Bond A.R.F. 2010: Road barrier effect on small birds removed by vegetated overpass in South East Queensland. - Ecol. Manag. Restor. 11: 65-67.

Kalkman V.J., Boudot J.-P., Bernard R., Conze K.-J., De Knijf G., Dyatlova E., Ferreira S., Jović M., Ott J., Riservato E. et AL. 2010: European Red List of Dragonflies. Publications Office of the European Union, Luxembourg, 38 pp.

Keller I. \& Largiadèr C.R. 2003: Recent habitat fragmentation caused by major roads leads to reduction of gene flow and loss of genetic variability in ground beetles. - Proc. R. Soc. (B) 270: $417-423$.

KrisKa G., Horváth G. \& ANdrikovics S. 1998: Why do mayflies lay eggs on dry asphalt roads? Water-imitating horizontally polarized light reflected from asphalt attracts Ephemeroptera. J. Exp. Biol. 201: 2273-2286.

MADER H.J. 1988: The significance of paved agricultural roads as barriers to ground dwelling arthropods. In Schreiber K.F. (ed.): Connectivity in Landscape Ecology. Münstersche Geographische Arbeiten, Münster, pp. 97-100.

Mader H.J., Schell C. \& Kornacker P. 1990: Linear barriers to arthropod movements in the landscape. - Biol. Conserv. 54: 209-222.

Martel J. 1995: Seasonal variations in roadside conditions and the performance of a gall-forming insect and its food plant. Environ. Pollut. 88: 155-160.

McKenna D.D., McKenna K.M., Malcom S.B. \& Bebenbaum M.R. 2001: Mortality of Lepidoptera along roadways in central Illinois. - J. Lepid. Soc. 55: 63-68.

Michiels N.K. \& Dhondt A.A. 1989: Differences in male and female activity patterns in the dragonfly Sympetrum danae (Sulzer) and their relation to mate-finding (Anisoptera: Libellulidae). - Odonatologica 18: 349-364.

MunguiRA M.L. \& Thomas J.A. 1992: Use of road verges by butterfly and burnet populations, and the effect of roads on adult dispersal and mortality. - J. Appl. Ecol. 29: 316-329.

MuÑoz P.T., TorRes F.P. \& Megías A.G. 2015: Effects of roads on insects: a review. - Biodivers. Conserv. 24: 659-682.

NoordijK J., Prins D., De Jonge M. \& Vermeulen R. 2006: Impact of a road on the movements of two ground beetle species (Coleoptera: Carabidae). — Entomol. Fenn. 17: 276-283.

Petranka J.W. \& Doyle E.J. 2010: Effects of road salts on the composition of seasonal pond communities: can the use of road salts enhance mosquito recruitment? - Aquat. Ecol. 44: 155-166.

R Development Core Team 2015: R: A Language and Environment for Statistical Computing. The R Foundation for Statistical Computing, Vienna. URL: https://www.r-project.org/.

Raebel E.M., Merckx T., Femer R.E., Riordan P., MacDonald D.W. \& THомpson D.J. 2012: Identifying high-quality pond habitats for Odonata in lowland England: Implications for agrienvironment schemes. - Insect Conserv. Div. 5: 422-432.

RAO R.S.P. \& GIRISH M.S. 2007: Road kills: assessing insect casualties using flagship taxon. - Curr. Sci. 92: 830-843.

RIFFELL S.K. 1999: Road mortality of dragonflies (Odonata) in a great lakes coastal wetland. - Gt. Lakes Entomol. 32: 63-74.

ŘSD ČR 2015: Czech Roads and Highways Directory. URL: https://www.rsd.cz/wps/portal/ (last accessed 8 Nov. 2016) [in Czech].

SchмiDt E.G. 2008: Sympetrum depressiusculum (Selys), a southern continental dragonfly depending on artificial habitats in Atlantic northwestern Germany (state of Northrhine-Westphalia) (Anisoptera: Libellulidae). — Notul. Odonatol. 7: 5-10. 
Seibert H.C. \& Conover J.H. 1991: Mortality of vertebrates and invertebrates on an Athens County, Ohio, highway. - Ohio J. Sci. 91: 163-166.

SEILER A. 2001: Ecological Effects of Roads: A Review. Introductory Research Essay no. 9. Swedish University of Agricultural Sciences, Uppsala, $40 \mathrm{pp}$.

Shepard D.B., Kuhns A.R., Dreslik M.J. \& Phillips C.A. 2008: Roads as barriers to animal movement in fragmented landscapes. - Anim. Conserv. 11: 288-296.

ŠIgutovÁ H., ŠIgUt M. \& DolnÝ A. 2015: Intensive fish ponds as ecological traps for dragonflies: an imminent threat to the endangered species Sympetrum depressiusculum (Odonata: Libellulidae). - J. Insect Conserv. 19: 961-974.

Skórka P., Lenda M., Moroń D., Kalarus K. \& Tryjanowski P. 2013: Factors affecting road mortality and the suitability of road verges for butterflies. - Biol. Conserv. 159: 148-157.

Soluk D.A., Zercher D.S. \& Worthington A.M. 2011: Influence of roadways on patterns of mortality and flight behavior of adult dragonflies near wetland areas. - Biol. Conserv. 144: $1638-1643$

SPELLERBERG I.F. 1998: Ecological effects of roads and traffic: a literature review. - Glob. Ecol. Biogeogr. Lett. 7: 317-333.

Sternberg K. \& Buchwald R. 2000: Die Libellen Baden-Württembergs. Band 2: Großlibellen (Anisoptera). Eugen Ulmer, Stuttgart, $712 \mathrm{pp}$.

Sternberg K. \& Sternberg M. 2004: Change of species composition and increased migration rate of dragonflies due to cutting of adjacent meadows of two running waters (Odonata). - $\mathrm{Li}$ bellula 23: 1-43.

Thomas C.D. 2000: Dispersal and extinction in fragmented landscapes. - Proc. R. Soc. (B) 267: 139-145.

Trombulak S.C. \& Frissell C.A. 2000: Review of ecological effects of roads on terrestrial and aquatic communities. - Conserv. Biol. 14: 18-30.

VAN BoHemen H.D. 1998: Habitat fragmentation, infrastructure and ecological engineering. - Ecol. Eng. 11: 199-207.

WILDERMUTH H. 2012: Extensively used meadows as habitat for maturation, forage and copulation of Coenagrion puella and Enallagma cyathigerum (Odonata: Coenagrionidae). - Libellula 31: 223-235.

Wood S.N. 2006: Generalized Additive Models: An Introduction with $R$. Chapman \& Hall/CRC Press, Boca Raton, FL, 410 pp.

Wood S.N. 2011: Fast stable restricted maximum likelihood and marginal likelihood estimation of semiparametric generalized linear models. - J. R. Stat. Soc. 73: 3-36.

Yamada Y., Sasaki H. \& Harauchi Y. 2010: Composition of road-killed insects on coastal roads around Lake Shikotsu in Hokkaido, Japan. - J. Rakuno Gakuen Univ. 34: 177-184.

Zahn A., Englmaier I. \& Drobny M. 2010: Food availability for insectivores in grasslands - arthropod abundance in pastures, meadows and fallow land. - Appl. Ecol. Environ. Res. 8: $87-100$.

Received June 5, 2017; revised and accepted August 29, 2017 Published online October 5, 2017 